\title{
Optimum Organization of the Labor Market in a Small Open Economy
}

Blomgren-Hansen, Niels

Document Version

Submitted manuscript

Publication date:

2008

License

CC BY-NC-ND

Citation for published version (APA):

Blomgren-Hansen, N. (2008). Optimum Organization of the Labor Market in a Small Open Economy. Department of Economics. Copenhagen Business School. Working Paper / Department of Economics.

Copenhagen Business School No. 3-2008

Link to publication in CBS Research Portal

\section{General rights}

Copyright and moral rights for the publications made accessible in the public portal are retained by the authors and/or other copyright owners and it is a condition of accessing publications that users recognise and abide by the legal requirements associated with these rights.

Take down policy

If you believe that this document breaches copyright please contact us (research.lib@cbs.dk) providing details, and we will remove access to the work immediately and investigate your claim.

Download date: 26. Apr. 2023 


\section{Department of Economics}

Copenhagen Business School

Working paper 3-2008

OPTIMUM ORGANIZATION OF THE LABOR MARKET IN A SMALL OPEN ECONOMY

Niels Blomgren-Hansen

$\overline{\text { Department of Economics -Porcelænshaven 16A, 1.fl. - DK-2000 Frederiksberg }}$ 


\title{
Optimum organization of the labor market in a small open economy
}

\author{
Niels Blomgren-Hansen \\ Department of Economics, Copenhagen Business School* \\ May 2008
}

\begin{abstract}
In most countries labor is organzed in cooperating skill-specific unions rather than in industrial unions or separately bargaining skillspecific unions. Within an extremely simple model of a small open economy facing imperfect competition we show that this way of organizing labor can be explained as the outcome of rational (optimizing) behavior on the part of the unions and the employers. Organizing labor in local industrial cartels (regardless of skill) or a single economy wide cartel results in a real wage level that is inappropriately low both from the point of view of labor and the society as a whole unless labor has close to monopoly power in the wage setting process. Organizing labor in local or economy wide skill-specific unions may result in a wage level that is too high. In addition, a labor market organized in non-cooperating unions is likely to be unstable. This dilemma calls for a compromise: A cartel of cooperating, independent skill-specific unions. The degree and the form of the cooperation depend inter alia on the bargaining power of the employer, the number of skills and competing firms and the rigidity with which the unions enforce lines of demarcations.

JEL classification: D23; J5.

Keywords: Labor market organization, Unions, Industrial Cartels, Demarcations
\end{abstract}

*Address: 16A Porcelaenshaven, DK-2000 Frederiksberg C, Denmark. Tel. $+(45)$ 38152588, E-mail: nbh.eco@cbs.dk 


\section{Introduction}

In most countries labor is organized in cooperating skill-specific unions rather than in industrial cartels or separately bargaining skill-specific unions (see e.g. Andersen and Risager 1990, Moene, Wallerstein and Hoel 1993, Scheuer 1995).

The aim of this paper is to present a model that can explain this phenomenon as the outcome of rational (optimizing) behavior on the part of the unions.

The model presented falls within the utility-maximizing-union strand of literature. Its main distinguishing characteristics are: (1) Many, possibly cooperating, skill-specific unions and many firms, (2) Closed-shop unionism, (3) Simultaneous wage-rate bargaining, (4) Employers' right to manage, (5) Union enforced demarcations, and (6) Specialized-small-open-economy macroeconomic framework. Within this set-up we analyze the optimum organization of labor from the point of view of labor as a function of market characteristics, technology and preferences.

The determinants of the way labor is organized and the impact on the economy have been the topic of several papers. Important contributions based on set-ups more or less resembling ours are Oswald (1979), Hersoug (1983), Horn and Wolinsky (1988), Gylfason and Lindbeck (1984), Jun (1989), Dowrick (1989), Holden and Raaum (1991), Moene, Wallerstein and Hoel (1993), De Fraga (1993), Machin, Steward and van Reenen (1993) and Naylor (1995). However, to our knowledge the combination of distinguishing characteristics and the specific way in which they are modelled are novel and open up for additional insights.

The economy modelled may be characterized as a 'sausage' economy. There is only one industry. The industry consists of $n$ firms, each one located on a separate 'island' (i.e. factors are immobile between firms). All firms have identical production technology and produce a homogeneous product. The only input is labor. Labor comes in $m$ different skills. Each skill group is of identical size, and the elasticity of substitution between any pairs of skills is the same. Labor decides the organization of the labor market. The utility function of the representative union member reflects risk aversion (in the sense that the elasticity of utility with respect to the probability of being employed is larger that the elasticity of utility with respect to the wage rate, Dowrich 1989, de Fraga 1993) or insider power (in the sense that the unions

represent insiders who are protected by seniority and consequently cares little 
about the risk of being priced out of the market, Moene 1988) as well as 'envy' (in the sense that relative wages matter, Gylfason and Lindbeck 1983, Paldam 1989, Moene, Wallerstein and Hoel 1993). The wage rates are determined jointly by the unions and the employers in a Nash bargaining process. The firms have the right to manage; i.e. the firms determine unilaterally the level and composition of employment. All production is exported and all consumption goods imported. (Export) demand is a declining function of price. Consequently, an increase in production and employment comes at the cost of declining real wages and deteriorating terms of trade. Real national income, contrary to employment and production, is not a monotonically declining function of the real wage rate. This observation poses the question: Which way of organizing the labor market results in highest union utility, respectively, the highest real national income?

Within this simple setting we analyze the impact of four 'clean' ways of organizing labor: (1) Non-cooperating skill-specific local unions, (2) Local (firm-level) industrial cartels, (3) Economy-wide skill-specific (joint) unions, and (4) A single national industrial cartel. In cases (1) and (3) we extend the analysis to encompass the empirically important fact that unions may enforce demarcations, which reduce the feasible elasticity of substitution among skills below the technically determined elasticity of substitution. As noted by Hersoug (1983), where technical conditions allow substitution the union will gain by enforcing 'artificial' substitution barriers.

Given the fact that all workers are assumed only to differ by skill and location one might conjecture that labor would choose to fully centralize wage negotiations: An all-encompassing union can always mimic the best decentralized solution or do better. This conjecture is not true (as would be the case if labor had the power to set the wage rate unilaterally). Decentralized and uncoordinated wage negotiations between the firms and 'selfish' unions, each of which empowered with the ability to hurt the firm(s) by calling a strike, may increase the bargaining position of labor and possibly result in a better outcome from the point of view of both labor and the economy as a whole than a totally centralized bargaining process (Horn and Wolinsky 1988, Holden and Raaum 1991, Machin, Steward and van Reenen 1993, Naylor 1995). In fact, within the model presented, the union utility maximizing wage level (as well as the real national income maximizing wage level) is unattainable if labor is organized in either separately bargaining skill-specific craft unions or in all-encompassing industrial unions. Contrary to Calmfors and Drifill (1988), who conclude that a decentralized labor market and a fully 
centralized labor market are superior to 'in-between' solutions, we find that cooperating sovereign craft unions as observed in many successful economies is, indeed, the optimum way of organizing labor.

The combination of independence and cooperation raises two problems which appear generally overlooked in the literature. Independent actions may turn the Nash-equilibrium solution unstable and too tight cooperation may be incentive incompatible. The solution to both problems appear to be carefully designed rules of the game.

The structure of the paper is as follows: In part 2 we set up the model and determine employment, real national income and union utility as functions of the equilibrium wage rate. In part 3 we solve the model and derive the equilibrium wage rate under alternative ways of organizing the labor market In part 4, we compare the results and analyze the conditions under which each organizational form is optimal from the point of view of labor and from the point of view of the society as a whole. In part 5, we address the stability and incentive compatibility problems facing joint unions and establish the necessary conditions for cartels to be incentive compatible. Part 6 sums up the results of the analysis.

\section{The basic framework}

\subsection{The profit function of the representative firm}

The $n$ firms in the industry produce a homogeneous product using identical CES production technology

$$
q_{i}=\left(m^{\frac{-1}{\sigma}} \cdot \sum_{j=1}^{m} L_{i j}^{\frac{\sigma-1}{\sigma}}\right)^{\frac{\sigma}{\sigma-1}}
$$

where $q_{i}=$ the production of the $i$ 'th firm, $m=$ the number of skills (and local unions), $L_{i j}=$ the employment of workers with skill $j$ in firm $i$ and $\sigma=$ the elasticity of substitution between any two pairs of skills $(\sigma \geqq 0)$ 
The corresponding unit cost functions and labor demand functions are

$$
\begin{aligned}
c_{i} & =\left(\frac{1}{m} \cdot \sum_{j=1}^{m} w_{i j}^{(1-\sigma)}\right)^{\frac{1}{1-\sigma}} \\
L_{i j} & =\frac{q_{i}}{m} \cdot\left(\frac{c_{i}}{w_{i j}}\right)^{\sigma}
\end{aligned}
$$

where $c_{i}$ is the unit cost of the $i^{\prime}$ th firm and $w_{i j}$ is the wage rate of workers with skill $j$ in firm $i$.

Note that the specification of the production function implies that production is equal to employment, $q_{i}=\sum L_{i j}=L_{i}$, if the $m$ skills are of identical size, $L_{i j}=\frac{L_{i}}{m}$. Correspondingly, if all workers in a firm receive the same wage rate regardless of skill, $w_{i j}=w_{i}$, then the unit production cost is equal to the wage rate, $c_{i}=w_{i}$.

The demand function is assumed to be linear ${ }^{1}$,

$$
Q=A-b \cdot P
$$

and the market characterized by Cournot competition.

The (inverse) demand curve facing the representative firm in a is

$$
p_{i}=P=\frac{1}{b} \cdot(A-Q)=\frac{1}{b} \cdot\left(A-\sum_{j=1}^{n} q_{j}\right)
$$

The representative firm's profit maximizing supply is

$$
q_{i}=\frac{A}{2}-\frac{c_{i} \cdot b}{2}-\frac{\sum q_{j}}{2}, i \neq j
$$

The solution of the system of $n$ supply equations

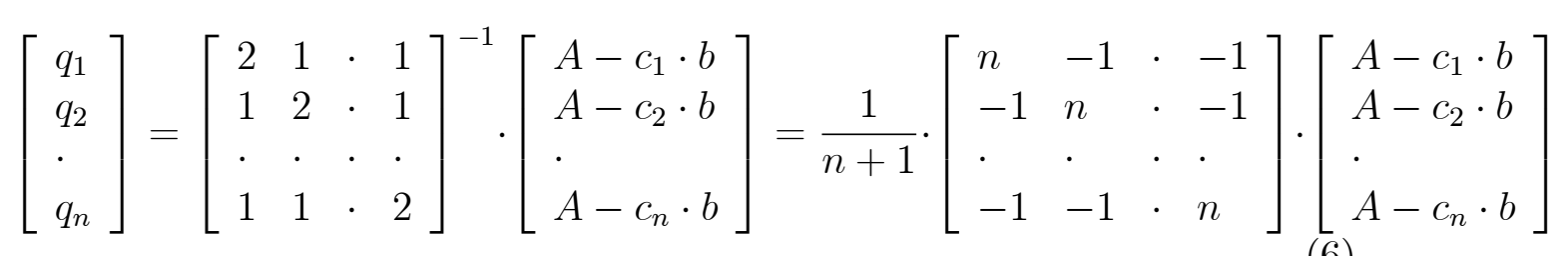

\footnotetext{
${ }^{1}$ The assumed linearity is crucial. It implies that the higher the equilibrium wage rate (unit cost) the higher the price and, consequently, the higher the elasticity of demand. Dowrich (1989) assumes that the demand function is isoelastic, and Holden and Raaum (1991) that the econo ny is completely open, i.e. that the pricelevel is exogenously determined.
} 
is

$$
q_{i}=\frac{1}{n+1} \cdot\left(A-n \cdot c_{i} \cdot b+\sum_{j=1, j \neq i}^{n} c_{j} \cdot b\right)
$$

from which we derive the market supply, the market price, and the profit of the representative $i$ th firm

$$
\begin{aligned}
Q & =\frac{1}{n+1} \cdot\left(n \cdot A-b \cdot \sum_{j=1}^{n} c_{j}\right) \\
P & =\frac{1}{n+1} \cdot\left(\frac{A}{b}+\sum_{j=1}^{n} c_{j}\right) \\
\Pi_{i} & =\left(q_{i}\right)^{2}=\left(\frac{1}{n+1}\right)^{2} \cdot \frac{1}{b} \cdot\left(A-n \cdot c_{i} \cdot b+b \cdot \sum_{j=1, j \neq i}^{n} c_{j}\right)^{2}
\end{aligned}
$$

\subsection{The union utility function}

The total labor force $L$ is normalized to one. Labor is assumed immobile between locations (firms) and skills. The labor force in each location is $\frac{1}{n}$. Each local union organizes $\frac{1}{n \cdot m}$ of the labor force.

Unions are assumed to maximize the utility of a representative worker. For simplicity the utility function is isoelastic in the probability of being employed, gross income and relative income:

$$
V_{i j}=\left(L_{i j} \cdot n \cdot m\right)^{\gamma} \cdot w_{i j} \cdot\left(\frac{w_{i j}}{c_{i}}\right)^{\phi}
$$

The utility function reflects two psychological characteristics of most human beings: (1) risk aversion and (2) 'envy'.

$L_{i j} \cdot n \cdot m$ is the employment rate of the workers organized by the $j$ 'th union at the $i$ 'th location $\left(=\frac{1}{n \cdot m}\right)$. Consequently, $L_{i j} \cdot n \cdot m \leq 1$ is also the probability that a representative worker at location $i$ organized in union $j$ becomes employed. If he is employed, he receives the income $w_{i j}$; if unemployed, he receives nothing. His expected income is $L_{i j} \cdot n \cdot m \cdot w_{i j}$. If he is risk averse, he prefers a somewhat smaller risk-free income to a given expected but risky income, i.e. $\gamma>1 . \gamma=1$ corresponds to the case where the union maximizes expected or average income. 
Alternatively, $\gamma<1$ may be interpreted as a measure of insider power. Insiders are protected by seniority and, consequently, care less about the effect on employment of a wage increase. Pemberton (1988) argue that the union utility function reflect the median voter (ordered by seniority). In the extreme case (Moene 1988) unions totally disregard the risk of unemployment and care only about the wage rate, $\gamma=0$.

The last term of the utility function is the relative wage rate of the representative worker compared to the average of the wage rates of all workers in the same location (firm). Income is an important measure of a person's po-

sition in society. The parameter $\phi \geq 0$ measures the value the representative worker attaches to position.

\subsection{Solution of the model for a given wage rate}

Substituting (7) into (3) for the resulting expression into (11) gives the utility of the representative worker in the $(i, j)$ 'th union as a function of his own wage rate, the unit costs in his own firm and the wage costs of competing firms,

$$
V_{i j}=\left(\frac{n}{n+1}\right)^{\gamma} \cdot\left(A-b \cdot n \cdot c_{i}+b \cdot \sum_{j=1, j \neq i}^{n} c_{j}\right)^{\gamma} \cdot c_{i}^{\gamma \cdot \sigma-\phi} \cdot w_{i j}^{1+\phi-\gamma \cdot \sigma}
$$

In symmetric equilibrium all wage rates are equal, $w_{i j}=c_{i}=c$, and the solution of the model as a function of $c$ reduces to

$$
\begin{aligned}
q_{i} & =\frac{1}{n+1} \cdot(A-c \cdot b) \\
L & =Q=\frac{n}{n+1} \cdot(A-c \cdot b) \\
P & =\frac{1}{n+1} \cdot\left(\frac{A}{b}+n \cdot c\right) \\
\Pi & =\frac{n}{(n+1)^{2}} \cdot \frac{1}{b} \cdot(A-c \cdot b)^{2} \\
V_{i j} & =\left(\frac{n}{n+1}\right)^{\gamma} \cdot(A-c \cdot b)^{\gamma} \cdot c \\
Y & =Q \cdot P=\frac{n}{(n+1)^{2}} \cdot \frac{1}{b} \cdot(A-b \cdot c) \cdot(A+b \cdot n \cdot c)
\end{aligned}
$$


Unsurprisingly, production $(Q)$, employment $(L)$ and profits $(\Pi)$ are monotonically declining functions and the price level (= terms of trade) $(P)$ a monotonically increasing function of the wage rate. Union utility $(V)$ and real national income in units of imported goods $(Y)$ depend not just on the level of employment but also on, respectively, the real wage rate $(c)$ and the terms of trade $(P)$. Consequently, the effect on these variables of a wage increase is ambiguous.

From eq. (17) and (18) we may derive the equilibrium wage rate that maximizes union utility, respectively real national income,

$$
\begin{aligned}
c_{V}^{*} & =\frac{A}{b} \cdot \frac{1}{1+\gamma} \\
c_{Y}^{*} & =\frac{A}{b} \cdot \frac{n-1}{2 \cdot n}
\end{aligned}
$$

As illustrated in figure $1^{2}$, an increase in the wage level improves union utility, if $c<c_{V}^{*}$ and raises real national income if $c<c_{Y}^{*}$. The wage rate that maximizes real income may be higher than the wage rate that maximizes union utility.

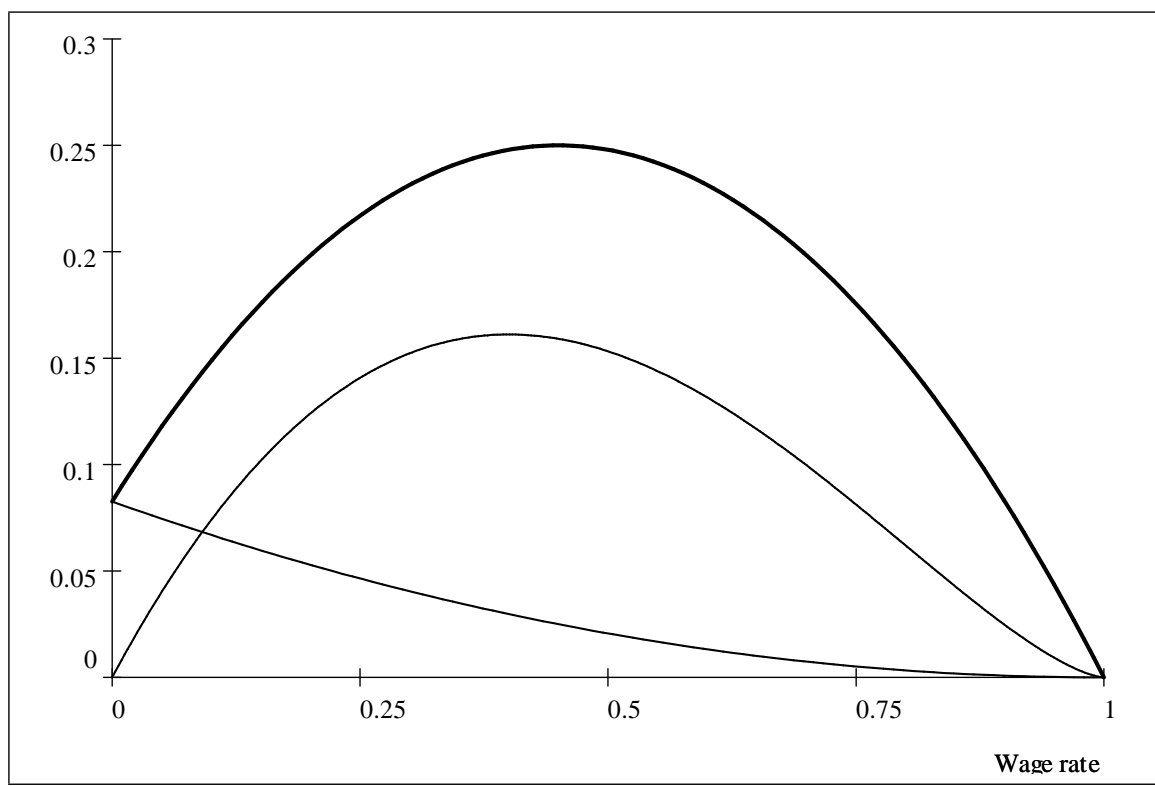

Figure 1: Real national income (thick solid line), Union utility (thin solid line) and Profits (thin dashed line) as functions of the wage rate

\footnotetext{
${ }^{2}$ The graph is drawn on the following assumptions: $A=b=1 ; \gamma=1.5 ; n=10$. The corresponding maximizing wage rates are $c_{Y}^{*}=0.48$ and $c_{V}^{*}=0.40$.
} 


\section{Determination of the wage level}

The wage level is determined in a Nash bargaining process. The maximizing wage rate depends not just upon the bargaining power of the unions $(\varepsilon)$ and the parameters of the union utility function $(\gamma$ and $\phi)$, the competition in the goods market (the number of competitors, $n$ ), the number of skills $(m)$ and the competition among skills (measured by the elasticity of substitution $\sigma)$ but also on the way in which the labor market is organized.

In the following we analyze four different ways of organizing the labor market: (a) Local, skill-specific unions $(L U)$, (b) Economy-wide (or joint) skill-specific unions $(J U)$, (c) Local industrial cartels $(L I C)$, and (d) An economy-wide (national) industrial cartel $(N I C)$.

In addition to these four distinct ways of organizing labor we consider the case of limited cooperation among skill-specific unions in the form of agreements as to which union has the right to organizing a given function. These so-called demarcations reduce the possibility of the employers to substitute workers of one skill for workers of another skill below what would be possible for purely technological reasons,

$$
0 \leq \sigma_{\text {feasible }}<\sigma
$$

Reduced competition among skills strengthens the bargaining position of the unions ${ }^{3}$.

\subsection{Non-cooperating local unions (LU)}

In this subsection we assume that every individual local union engages in wage bargaining with its employer taking the wage level of all other unions local as well as those organizing labor in competing firms - as given. Admittedly, this assumption is not very realistic. In particular, an employer might take into account that a wage hike given to one union has an effect on the

\footnotetext{
${ }^{3}$ To give an example from the history of labor relations in Denmark, typographers and lithographers might easily substitute each other. The technological elasticity of substitution was high. However, the unions agreed upon which functions should be carried out by typographers and which functions should be carried out by lithographers and they were willing and able to enforce the agreed line of demarcation. As a consequence, the wage level of typographeras and lithograhers was significantly higer than that of skills with similar length of education. Eventually, their powerbase dissolved due to the development of IT-technology.
} 
wage demands of the other unions - positively or negatively depending on the slope of the reaction functions. However, the case is a natural and useful benchmark for evaluating the impact of union cooperation across skills and locations.

The wage rate $w_{i j}$ is determined by maximizing (the logarithm of) the asymmetric Nash expression

$$
\ln N_{L U}=\varepsilon \cdot \ln \left(V_{i j}-V_{i j}^{*}\right)+(1-\varepsilon) \ln \left(\Pi_{i}-\Pi_{i}^{*}\right)
$$

with respect to $\ln \left(w_{i j}\right)$ assuming all other wage rates remain constant.

The definition of the disagreement points $V_{i j}^{*}$ and $\Pi_{i}^{*}$ is crucial (Binmore et al.1986). The terms denote, respectively, union utility and firm profit in case no agreement is reached, and the union calls a strike or the employer a lock-out. To simplify the calculations we shall assume that both $V_{i j}^{*}$ and $\Pi_{i}^{*}$ are zero ${ }^{4}$. The parameter $\varepsilon, 0 \leq \varepsilon \leq 1$, measures the exogenously determined bargaining power of the union, and $1-\varepsilon$ that of the employer.

Substituting (12) for $V_{i j}$ in (21), (2) for $c_{i}$ and (10) for $\Pi_{i}$ and maximizing the resulting expression with respect to $w_{i j}$ gives the first order condition

$$
\begin{aligned}
& (\varepsilon \cdot \gamma+2 \cdot(1-\varepsilon)) \cdot\left(\frac{-n \cdot c_{i}}{A-n \cdot b \cdot c_{i}+b \cdot \sum_{j \neq i}^{n} c_{j}}\right) \cdot \frac{1}{m} \cdot\left(\frac{c_{i}}{w_{i j}}\right)^{\sigma-1} \\
& +(\varepsilon \cdot(\gamma \cdot \sigma-\phi)) \cdot \frac{1}{m} \cdot\left(\frac{c_{i}}{w_{i j}}\right)^{\sigma-1}+\varepsilon \cdot(1+\phi-\gamma \cdot \sigma)=0 ; j \neq i
\end{aligned}
$$

Symmetric equilibrium implies that $w_{i j}=c_{i}=c$ for all unions and all firms. Imposing this restriction reduces eq. (22) to,

$$
\begin{aligned}
c_{L U} & =\frac{A}{b} \cdot \frac{m-(m-1) \cdot(\gamma \cdot \sigma-\phi)}{m-(m-1) \cdot(\gamma \cdot \sigma-\phi)+(\gamma+2 \cdot(1 / \varepsilon-1)) \cdot n} \\
& =\frac{A}{b} \cdot \frac{a}{a+d \cdot n} \\
a & \equiv m-(m-1) \cdot(\gamma \cdot \sigma-\phi) \\
d & \equiv \gamma+2 \cdot(1 / \varepsilon-1)>0
\end{aligned}
$$

${ }^{4} V_{i j}^{*}=0$ is consistent with the assumption that labor is immobile between locations (firms) and skills, and that striking workers have no alternative income. Striking workers may get financial support from the union, but as there is nobody to pay but the workers themselves, the support should be considered a loan. If the employer's righ to manage does not include the right to lay off non-striking workers, $\Pi_{i}^{*}$ is likely to be negative, unless the elasticity of substitution is pretty high. However, as explained below, in this case a positive solution is unlikely to exist. 
The solution is meaningful only if $c_{L U}>0$ and $q_{L U}=\frac{A}{n+1} \cdot\left(\frac{d \cdot n}{a+d \cdot n}\right)>0$. As $d$ is always non-negative, the non-negativity or existence condition reduces to $a>0$, i.e.

$$
\sigma<\sigma_{\max }=\left(\frac{m}{m-1}+\phi\right) \cdot \frac{1}{\gamma}
$$

If the non-negativity condition is not satisfied, the wage rates will be set at the union's reservation wage level, which in our model is zero. This solution is 'organizationally unstable' in the sense that labor has no incentive to organize (and pay to) unions unless the unions are able to raise the wage rate above the reservation wage level. The non-negativity condition is binding for plausible values of the parameters ${ }^{5}$. For $m=2, \phi=0$ and $\gamma=1, \sigma$ may not exceed 2 ; for $m=10, \phi=0.5$, and $\gamma=1.5$, a positive solution only exists if $\sigma<1.07$. In addition, an interesting solution must be stable. The derivation of the stability condition is given in section 5.2.

\subsection{Local industrial cartels (LIC)}

Organizing labor in local skill-specific unions implies that the various skills compete. This competition is neutralized if labor organize in local industrial cartels.

For simplicity we shall assume that the governing body of the local industrial cartel attaches equal weight to the utility of the representative member of each of the $m$ cooperating local unions ${ }^{6}$,

$$
V_{L I C, i}=\prod V_{i j}^{\beta_{j}} ; \quad \beta_{j}=\frac{1}{m}
$$

All members of the cartel get the same wage rate regardless of skill: $w_{i j}=c_{i}$. This implies that the substitution term $(\sigma)$ and 'envy' $(\phi)$ terms vanish and the number of skills $(m)$ become irrelevant. The union objective function reduces to

$$
V_{L I C}=\left(L_{i *} \cdot n \cdot m\right)^{\gamma} \cdot c_{i}=\left(q_{i *} \cdot n\right)^{\gamma} \cdot c_{i}
$$

\footnotetext{
${ }^{5}$ On the basis of Danish data for the period 1948-88, Risager (1993) estimated the elasticity of substitution between skilled and unskilled workers to about 1.3 on the aggregate level.

${ }^{6}$ In part 5.2 we argue that a wage setting cartel is incentive incompatible if it does not attach equal weights to the welfare of the representative member of all cooperating unions.
} 
Maximizing the corresponding Nash expression

$$
\ln N_{L I C}=\varepsilon \cdot \ln \left(V_{L I C}\right)+(1-\varepsilon) \ln \left(\Pi_{i}\right)
$$

with respect to $c_{i}$, assuming that unit costs of all other firms are constant, gives the first order condition

$$
\frac{\partial \ln N_{L I C}}{\partial c_{i}}=\frac{\varepsilon}{c_{i}}+(\varepsilon \cdot \gamma+2 \cdot(1-\varepsilon)) \cdot\left(\frac{-n \cdot b}{A-n \cdot b \cdot c_{i}+b \cdot \sum_{j \neq i}^{n} c_{j}}\right)=0
$$

from which we derive the unit cost and wage rate in symmetric equilibrium, $w=c=c_{i}=c_{j}$

$$
\begin{aligned}
c_{L I C} & =\frac{A}{b} \cdot \frac{1}{1+(\gamma+2 \cdot(1 / \varepsilon-1)) \cdot n} \\
& =\frac{A}{b} \cdot \frac{1}{1+d \cdot n}
\end{aligned}
$$

\subsection{Economy-wide skill-specific (joint) unions (JU)}

Typically, wage earners identify themselves more with their profession or skill than with other skill-groups in the firm in which they are employed and, supposedly, more so in former times than today. Consequently, workers traditionally organized in economy-wide skill-specific unions, which for short are denoted joint unions (JU).

A joint union organizing all employees with skill $j$ maximizes

$$
V_{J U}=\prod V_{i j}^{\alpha_{i}} ; \sum \alpha_{i}=1
$$

As above, we assume that the governing body of the joint union attaches equal weight to the welfare of all members, regardless of the firm in which they are employed, $\alpha_{i}=\frac{1}{n}$. This implies that the only way in which the game is changed is that the individual joint union and the employers now take into account that an increase in the wage rate of union $j$ has the same effect on the unit costs of all $n$ firms, $c_{i}=c$. The indirect competition between workers with identical skill employed by different firms is eliminated. The relative position of the individual firm is unaffected by a wage hike. The wage-setting game becomes equivalent to the game between one of $j$ unions and a single (monopoly) firm. 
Maximizing the corresponding Nash-expression

$$
\begin{aligned}
\ln N_{J U}= & \varepsilon\left(\gamma \cdot \ln \frac{1}{2}+\gamma \cdot \ln (A-b c)+(\gamma \sigma-\phi) \cdot \ln c+(1+\phi-\gamma \sigma) \cdot \ln w_{j}\right) \\
& +(1-\varepsilon) \cdot\left(\ln \frac{1}{4}-\ln b+2 \cdot \ln (a-b c)\right) \\
c= & \left(\frac{1}{m} \cdot \sum_{j=1}^{m} w_{j}^{(1-\sigma)}\right)^{\frac{1}{1-\sigma}}
\end{aligned}
$$

with respect to $w_{j}$ gives the first order condition

$$
\left((\varepsilon \gamma+2 \cdot(1-\varepsilon)) \frac{-b}{A-b c}+\varepsilon(\gamma \sigma-\phi) \frac{1}{c}\right) \frac{1}{m}\left(\frac{c}{w_{* j}}\right)^{\sigma}+\varepsilon(1-\gamma \sigma+\phi) \frac{1}{w_{* j}}=0
$$

from which, - making use of the symmetry assumption -we derive the $w_{j}=c$

$$
\begin{aligned}
c_{J U} & =\frac{A}{b} \cdot \frac{m-(m-1) \cdot(\gamma \cdot \sigma-\phi)}{m-(m-1) \cdot(\gamma \cdot \sigma-\phi)+\gamma+2 \cdot\left(\frac{1}{\varepsilon}-1\right)} \\
& =\frac{A}{b} \cdot \frac{a}{a+d}
\end{aligned}
$$

\subsection{A single economy-wide (national) industrial cartel (NIC)}

If labor wants to neutralize not just the competition among skills within the individual firm but also the competition from workers employed in other firms, they can do so by forming a single economy-wide (national) cartel.

The utility function of a single industrial cartel comprising all firms is

$$
V_{N I C}=\prod\left(\prod V_{i j}^{\beta_{j}}\right)^{a_{i}} ; \sum \alpha_{i}=1 ; \sum \beta_{j}=1
$$

If the cartel attaches equal weight to the welfare of the representative member of each local union regardless of skill and the firm in which they are employed, i.e. $\alpha_{i}=\frac{1}{n}$ and $\beta_{j}=\frac{1}{m}$, the joint utility function reduces to that of a representative local union $V_{N I C}=V_{i j}$. The Nash expression to be 
maximized with respect to $\ln (c)$ reduces to

$$
\begin{aligned}
\ln N_{N I C}= & \varepsilon \cdot\left(\gamma \cdot\left(\ln \left(\frac{n}{n+1}\right)+\ln (1-c)\right)+\ln (c)\right) \\
& +(1-\varepsilon) \cdot 2 \cdot\left(\ln \left(\frac{1}{n+1}\right)+\ln (1-c)\right)
\end{aligned}
$$

and the first order condition to

$$
\begin{aligned}
c_{N I C} & =\frac{1}{1+\gamma+2 \cdot\left(\frac{1}{\varepsilon}-1\right)} \\
& =\frac{1}{1+d}
\end{aligned}
$$

\section{Optimal choice of organization}

\subsection{Comparison of wage rates}

Figures 2 shows the (Nash-equilibrium) wage rate as a function of the elasticity of substitution and the way in which the labor market is organized ${ }^{7}$ : LU (lower curved line), LIC (lower horizontal solid line), JU (upper curved line ) and NIC (upper horizontal solid line). In addition, the figure depicts the optimum wage rate from the point of view of labor, $c_{V}^{*}=\frac{1}{1+\gamma}$, (thin dotted line) and the optimum (real national income maximizing) wage level from the point of view of society as a whole, $c_{Y}^{*}=\frac{n-1}{2 \cdot n}$ (thick dotted line).

\footnotetext{
${ }^{7}$ The figure is drawn for $n=10 ; m=10 ; \gamma=1.5$; and $\phi=0.5$. Union and the employers are assumed to have equal barganing power $(\varepsilon=0.5)$.
} 


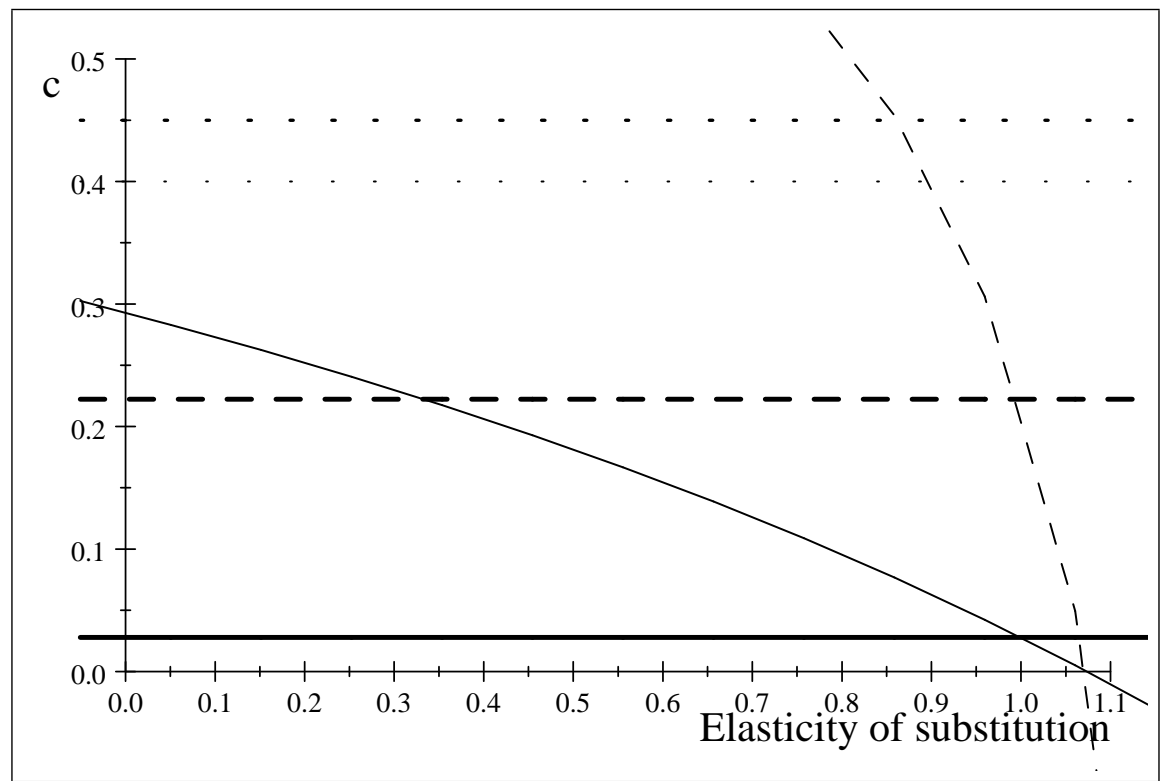

Figure 2: The wage rate as a function of the elasticity of substitution and way in which the labour market is organized

The figure illustrates a number of propositions which may readily be inferred from the analysis above:

1. Concentration matters: The equilibrium wage rate is higher if labor organizes in economy-wide (joint) skill-specific unions than if organized in local unions and higher if labor organizes in a single economy-wide (national) industrial cartel than if organized in local industrial cartels

$$
c_{J U}>c_{L U} ; c_{N I C}>c_{L I C}
$$

Proof: Follows directly from comparing eq. (24) and (36), respectively eq. (32) and (40).

Intuition: By forming economy-wide organizations rather than local labor neutralizes the (in)direct competition between workers of the same skill, respectively all other workers employed in competing firms.

2. Organizing labor by skill rather than by industry results in a higher equilibrium wage rate if and only if the adjusted rate of substitution is 
less than one ${ }^{8}$

$$
c_{L U}>c_{L I C} \text { and } c_{J U}>c_{N I C} \text { if } \sigma_{A d j} \equiv \frac{1+\phi}{\gamma}<1
$$

Proof: Comparing eq. (24) and (32), respectively eq. (36) and (40) shows that the sufficient and necessary condition is $\alpha>1$. From eq. (25) it follows that this is equivalent to $\sigma_{A d j} \equiv \frac{1+\phi}{\gamma}<1$.

Intuition: The share of total wage income that accrues to members of a skill-specific union is an increasing function of its relative wage rate if $\sigma<1$.

Corollary: If the unions by imposing demarcations can reduce the feasible rate of substitution sufficiently, then they can always raise the equilibrium wage rate to a higher level by organizing in skill-specific unions than by organizing in a single industrial cartel.

3. The most decentralized way of organizing the labor market $(L U)$ may result in a higher wage level (and a correspondingly lower level of production and employment) than the most centralized organization $(N I C)$. That will be the case if the elasticity of substitution and the number of firms are very low,

$$
c_{L U}>c_{N I C} \text { if } \sigma<\frac{1}{\gamma} \cdot\left(\phi+\frac{m-n}{m-1}\right)
$$

Proof: Comparing eq. (24) and (40) shows that $c_{L U}>c_{N I C}$ if $a>n$.

4. The ordering of the equilibrium wage rates as functions of the organization of the labor market is independent of the bargaining power of the unions $(\varepsilon)$.

Proof: Follows from the fact that none of the bilateral comparisons above depends on $d$.

Corollary: The ordering is also independent of the threat values $V_{0}$ and $\Pi_{0}$. That follows from the fact that rasing the threat value of one of the parties has an effect on the Nash-bargaining equilibrium that is

\footnotetext{
${ }^{8}$ Cf. Horn and Wollinsky (1988) who concludes that the equilibrium form of unionization is an encompassing union if the two types of labor are close substitutes and separate unions if the tow types of labor are sufficiently strong complements.
} 
equivalent to raising the same party's bargaining power. Consequently, the introduction of a tax-paid unemployment insurance system, which raises the threat value of labor will not affect the ordering of the equilibrium wage rates (but raise the wage level regardless of the way in which labor is organized).

5. The optimum wage level from the point of view of labor is lower than the optimum (income maximizing) wage level from the point of society as a whole if labor is risk averse $(\gamma>1)$ and the number of competing firms is 'large',

$$
c_{V}^{*}=\frac{A}{b} \cdot \frac{1}{1+\gamma}<c_{Y}^{*}=\frac{A}{b} \cdot \frac{n-1}{2 \cdot n} \text { if } \gamma>\frac{n+1}{n-1}
$$

Intuition: The income maximizing price is $P^{*}=\frac{A}{2 \cdot b}$. If $n$ is large and, consequently, $P \rightarrow c$, then the income maximizing wage rate is also $\frac{A}{2 \cdot b}$. All income accrues to labor. However, if workers are risk averse, they prefer a lower and less risky income, i.e. a higher rate of employment and a corresponding lower wage rate.

6. If labor does not have the power to set the wage rate unilaterally, then the wage rate resulting from organizing the labor market in industrial cartels (local or economy-wide) is always lower than the wage rate that maximizes union utility, respectively real national income

$$
c_{L I C}<c_{N I C}<c_{V}^{*}, \quad c_{L I C}<c_{N I C}<c_{Y}^{*}
$$

Proof: Follows from the fact that $d \equiv \gamma+2\left(\frac{1}{\varepsilon}-1\right)>\gamma$ for $\varepsilon<1$.

Corollary: The optimum way of organizing labor leaves some degree of autonomy to skill-specific unions.

7. Organizing labor in economy-wide skill-specific unions (and possibly in local skill-specific unions) is most likely to result in an equilibrium wage rate that is above the optimum level from the point of view of labour as well as from the point of view of society as a whole.

Proof: From eq. (36) and (19), respectively eq. (36) and 20) we have that

$$
c_{J U}>c_{V}^{*} \text { if } d<\gamma \cdot a ; \quad c_{J U}>c_{Y}^{*} \text { if } d<\frac{n+1}{n-1} \cdot a
$$


For each individual union it is a dominant strategy to defend 'its' jobs, i.e. impose the stiffest possible demarcation lines thereby reducing the feasible elasticity of substitution below the technically determined elasticity of substitution. In the extreme case of $\sigma_{\text {feasible }}=0$, the conditions may be written as

$$
\begin{aligned}
& c_{J U}>c_{V}^{*} \text { if } \varepsilon>\frac{2}{2+(m-1) \cdot(1+\phi) \cdot \gamma} \\
& c_{J U}>c_{Y}^{*} \text { if } \varepsilon>\frac{2}{2+\frac{n+1}{n-1} \cdot(m+(m-1) \cdot \phi)-\gamma}
\end{aligned}
$$

Corollary: The optimum way of organizing labor requires cooperation of skill-specific unions aiming at reducing the negative employment externatilities of uncoordinated actions.

\subsection{Preliminary conclusion}

From propositions 6 and 7 is follows that none of the identified 'clean' ways of organizing the labor market is ideal, neither from the point of view of labor nor from the point of view of society as a whole. The equilibrium wage rate becomes too low, if labor organizes in a single national industrial cartel, and too high, if labor organizes in economy-wide skill-specific unions and the unions pursue their dominant strategy of imposing stiff demarcations. ${ }^{9}$

This result indicates that the best way of organizing labor is a compromise between a single all-encompassing industrial cartel and independent skillspecific unions. ${ }^{10}$

In fact, this characterization of the optimum organization of labor appears to be a pretty precise description of the way labor is actually organized in many countries.

\footnotetext{
${ }^{9}$ Cf. Hersoug (1989) who finds that the cooperative equilibrium wage rate is lower than the Nash equilibrium wage rate if the skills are perfect complements.

${ }^{10}$ Machin, Steward and van Reenen (1993) argue that it is essential to distinguish between multiple unionism separate bargaining and multiple unionism joint bargaining. In an empirical analysis they find that plants with multiple unions and separate bargaining arrangements pay higher wages compared to single union plants and plant with multiple unions that bartgain jointly.
} 


\section{$5 \quad$ Stability and incentive compatibility}

\subsection{The intrinsic instability of a labor marked orga- nized by skills}

The (Nash-equilibrium) wage rate determined in a labor market organized in independent skill-specific unions is likely to be unstable.

To see that assume that in every period union $i j$ and the employer $i$ agree on an adjustment of the wage rate $w_{i j}$ assuming that the wages rates of $n \cdot m-1$ other groups remain constant.

The adjustment process may be formalized as

$$
\begin{aligned}
\Delta w_{t} & =A \cdot \Delta w_{t-1} \\
& =A^{n} \cdot \Delta w_{t-n}
\end{aligned}
$$

where $w$ is a vector of wage rates of length $n \cdot m$ and $A$ the corresponding transition matrix.

Consider the first row of $A$. The first element is 0 . The next $m-1$ elements are $\frac{\partial w_{11}}{\partial w_{1 k}}, k=2, . ., m$. The remaining $(n-1) \cdot m$ elements are $\frac{\partial w_{11}}{\partial w_{h k}}$, $h=1, . ., n, k=1, . ., m$. The symmetry assumption implies that all $\frac{\partial w_{11}}{\partial w_{1 k}}$ are identical $\left(=\kappa_{1}\right)$ and all $\frac{\partial w_{11}}{\partial w_{h k}}$ are identical $\left(=\kappa_{2}\right)$. All rows contain the same elements, although in differing order.

The largest eigenvalue of $A$ is

$$
\begin{aligned}
\lambda & =\lambda_{1}+\lambda_{2} \\
\lambda_{1} & =(m-1) \cdot \kappa_{1} ; \quad \lambda_{2}=(n-1) \cdot m \cdot \kappa_{2}
\end{aligned}
$$

and the associated eigenvector is a unit vector, $u$, of length $n \cdot m$

The wage determining process is stable if and only if $|\lambda|<1^{11}$.

To derive $\kappa_{1}=\frac{\partial w_{i j}}{\partial w_{i k}}$ and $\kappa_{2}=\frac{\partial w_{i j}}{\partial w_{h k}}$ we take the total derivative of $(22)$

\footnotetext{
${ }^{11}$ Oswald (1979) assumes that all off-dioganal elements are positive and concludes that stability requires that the off-dioganal elements og each row must sum to less than one. Otherwise, loosely speaking, the system is so highly interdepebndent that anly deviation from equuilibrium produces an explosive wage-wage spiral.
} 
and substitute $(24)$ for $w_{i j}=c_{i}=c_{j}$ in the resulting expression,

$$
\begin{aligned}
& \kappa_{1}=\frac{\partial w_{i j}}{\partial w_{i k}}=\frac{1-\frac{(a+d) \cdot a}{m \cdot(1-\gamma \cdot \sigma+\phi) \cdot(1-\sigma) \cdot d}}{(m-1)+\frac{(a+d) \cdot a}{m \cdot(1-\gamma \cdot \sigma+\phi) \cdot(1-\sigma) \cdot d}} \lessgtr 0 \\
& \kappa_{2}=\frac{\partial w_{i j}}{\partial w_{h j}}=\frac{\frac{a^{2}}{n \cdot m \cdot(1-\gamma \cdot \sigma+\phi) \cdot(1-\sigma) \cdot d}}{(m-1)+\frac{(a+d) \cdot a}{m \cdot(1-\gamma \cdot \sigma+\phi) \cdot(1-\sigma) \cdot d}} \geq 0
\end{aligned}
$$

The ancillary variables $a$ and $d$ are defined in eq. (25) and (26).

The stability condition $\left|\lambda=(m-1) \cdot \kappa_{1}+(n-1) \cdot m \cdot \kappa_{2}\right|<1$ is complicated and difficult to interpret analytically. In stead we rely on analogies to simple cases and simulations.

\subsubsection{Stability in case of economy-wide skill-specific unions $(n=1)$}

In the case labor is organized in economy-wide skill-specific unions (JU), there is no competition among workers having the same skill employed in different firms. $\lambda$ reduces to $\lambda_{1}$.

Consider the simplest possible case of two unions. The elasticity of substitution is zero, workers are risk neutral and do not suffer from envy: $n=1$, $m=2, \sigma=0, \gamma=1, \phi=0$. The ancillary variables reduce to $a=m=2$; $d=\frac{2-\varepsilon}{\varepsilon}$. The unions maximize the expected income of their members. Due to normalization chosen above, each union's employment rate is equal to $Q$. Further, and inconsequentially, we have normalized $A=b=1$.

For $\varepsilon=1$ (each union has monopoly power to dictate its wage rate) we get

$$
\begin{aligned}
c & =\frac{w_{1}+w_{2}}{2} ; \quad Q=\frac{1-c}{2}=\frac{1}{2}-\frac{w_{1}}{4}-\frac{w_{2}}{4} \\
V_{i} & =\left(\frac{1}{2}-\frac{w_{i}}{4}-\frac{w_{-i}}{4}\right) \cdot w_{i}
\end{aligned}
$$

Each union maximizes its utility, $V_{i}$ with respect to its wage rate. That gives the first order condition (reaction function) $)^{12}$

$$
w_{i}=1-\frac{1}{2} \cdot w_{-i}
$$

\footnotetext{
${ }^{12}$ Cf. Hersoug (1983) who as an example analyses a similar model (linear demand function and two perfectly complementary skills.
} 
and the equilibrium solution

$$
w_{1}=w_{2}=c=\frac{2}{3} ; \quad Q=\frac{1}{6} ; \quad P=\frac{5}{6} ; \quad V_{i}=\frac{1}{6} \cdot \frac{2}{3}=\frac{1}{9}
$$

The two skills are assumed to be perfect complements, $\sigma=0$, and, consequently, the reaction function is negatively sloped, $\lambda=\kappa_{1}=-\frac{1}{2}$. If one union for some reason raises its wage rate above the equilibrium rate, the optimum reaction of the other union is to reduce its rate $\mathrm{e}^{13}$.

Oswald (1979), Gylfason and Lindbeck (1984) and de Fraga (1993) assume that skills are gross substitutes and, consequently, that the reaction functions are positively sloped. This is not an innocuous assumption. In fact, in the two-monopoly-union case the reaction function is negatively sloped at the equilibrium wage rate unless the elasticity of substitution is rather high and the equilibrium wage rate correspondingly low.

This is illustrated in figure 3, which depicts the unions' reaction functions in case of $\sigma=0,0.5,1,1.25,1.5$, and 1,75 . The corresponding equilibrium wage rates are $0.67,0.6,0.5,0.43,0.33$, and 0.2 . For $\gamma=1$ and $\phi=0$ - no risk aversion and envy effects - the reaction functions are positively sloped at equilibrium only if the elasticity of substitution exceeds 1.6.

\footnotetext{
${ }^{13}$ To understand why, it may be illustrative to calculate the elasticity of the $i^{\prime} t h$ union's employment rate $(=Q)$ with respect to its wage rate, $w_{i}$ :$$
E_{Q, w_{1}}=E_{Q, P} \cdot E_{P, c} \cdot E_{c, w_{1}}=\left(1-\frac{\frac{5}{6}}{\frac{1}{6}}\right) \cdot\left(\frac{1}{2} \cdot \frac{\frac{2}{3}}{\frac{5}{6}}\right) \cdot\left(\frac{1}{2} \cdot \frac{\frac{2}{3}}{\frac{2}{3}}\right)=-5 \cdot 0.4 \cdot 0.5=-1
$$

As any other monopoly that faces no cost of production (the reservation wage rate is assumed to be zero) the monoply union set its price (wage rate) such that the elasticity of demand for its product (workers organized in the union) is -1. Assume that union 2 rises its wage rate $w_{2}$ by $x$. That will cause an increase of $c$ by $\frac{x}{2}$ and reduce production and the employment rate by $\frac{x}{4}$. $E_{Q, w_{1}}$ falls below -1 . Union 1's optimal reaction is to reduce its wage rate.
} 


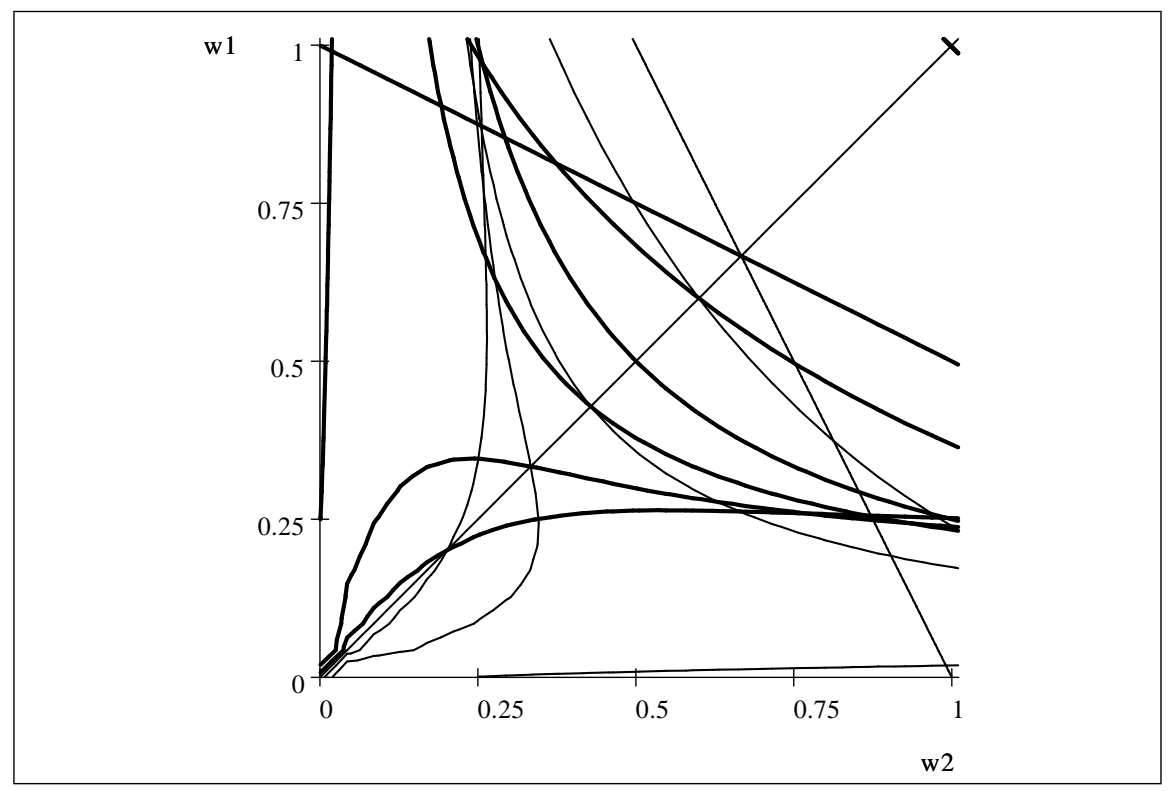

Figure 3: Reaction functions in case of two monopoly unions for various values of the elasticity of substitution. w1(w2) thick line, w2(w1) thin line.

In the two-monopoly-union case the Nash-equilibrium is stable (although indeterminate for $\sigma=1$ ).

This is not necessarily the case if $m>3$.

As in the simplified two-union case assume that all skills are perfect complements, $\sigma=0$, and that each union unilaterally sets the wage rate for the workers it organizes, $\varepsilon=1$.

Unit costs, production (and employment rate), price and expected income of members of union no 1 (union utility) are given by

$$
\begin{aligned}
c & =\frac{1}{m} \cdot \sum_{j=1}^{m} w_{j} ; Q=\frac{1}{2 m} \cdot\left(m-\sum_{j=1}^{m} w_{j}\right) \\
P & =\frac{1}{2 m} \cdot\left(m+\sum_{j=1}^{m} w_{j}\right) ; V_{1}=\frac{1}{2 m} \cdot\left(m-\sum_{j=1}^{m} w_{j}\right) \cdot w_{1}
\end{aligned}
$$

Maximizing $V_{1}$ with respect to $w_{1}$ gives the first order condition (reaction function) and corresponding (maximum) root of the transition matrix,

$$
w_{1}=\frac{m}{2}-\frac{1}{2} \cdot \sum_{j=2}^{m} w_{j} ; \quad \lambda=-\frac{m-1}{2}<-1
$$


The Nash equilibrium is unstable, $|\lambda|>1$ In case one union's wage rate differs from the equilibrium level, the vector of wage rates will diverge from the Nash equilibrium through progressively increasing fluctuations:

$$
\begin{aligned}
& {\left[\begin{array}{l}
\Delta w_{1} \\
\Delta w_{2} \\
\Delta w_{3} \\
\Delta w_{4}
\end{array}\right]_{0}=\left[\begin{array}{l}
x \\
0 \\
0 \\
0
\end{array}\right] ;\left[\begin{array}{l}
\Delta w_{1} \\
\Delta w_{2} \\
\Delta w_{3} \\
\Delta w_{4}
\end{array}\right]_{1}=\left[\begin{array}{cccc}
0 & -0.5 & -0.5 & -0.5 \\
-0.5 & 0 & -0.5 & -0.5 \\
-0.5 & -0.5 & 0 & -0.5 \\
-0.5 & -0.5 & -0.5 & 0
\end{array}\right]\left[\begin{array}{l}
x \\
0 \\
0 \\
0
\end{array}\right]=\left[\begin{array}{c}
0 \\
-0.5 x \\
-0.5 x \\
-0.5 x
\end{array}\right]} \\
& {\left[\begin{array}{l}
\Delta w_{1} \\
\Delta w_{2} \\
\Delta w_{3} \\
\Delta w_{4}
\end{array}\right]_{2}=\left[\begin{array}{l}
0.75 x \\
0.5 x \\
0.5 x \\
0.5 x
\end{array}\right] ;\left[\begin{array}{l}
\Delta w_{1} \\
\Delta w_{2} \\
\Delta w_{3} \\
\Delta w_{4}
\end{array}\right]_{3}=\left[\begin{array}{c}
-0.75 x \\
-0.875 x \\
-0.875 x \\
-0.875 x
\end{array}\right] ;\left[\begin{array}{l}
\Delta w_{1} \\
\Delta w_{2} \\
\Delta w_{3} \\
\Delta w_{4}
\end{array}\right]_{4}=\left[\begin{array}{c}
1.3125 x \\
1.25 x \\
1.25 x \\
1.25 x
\end{array}\right]}
\end{aligned}
$$

Employer power attenuates but does not solve the intrinsic instability problem.

For $\varepsilon<1$ and $\sigma=0$ the Nash-expression to be maximized in the bargaining process between the employer and the union no. 1 is

$$
N_{1}=\varepsilon \cdot \ln V_{1}+(1-\varepsilon) \cdot \ln \Pi=(\varepsilon+2 \cdot(1-\varepsilon)) \cdot \ln \left(\frac{1}{4} \cdot\left(2-w_{1}-\sum_{j=2}^{m} w_{j}\right)\right)+\varepsilon \cdot \ln w_{1}
$$

The f.o.c. and the maximum root of the transition matrix are, respectively

$$
w_{1}=\varepsilon \cdot\left(1-\frac{1}{2} \cdot \sum_{j=2}^{m} w_{j}\right) ; \quad \lambda_{1}=-\frac{\varepsilon}{2} \cdot(m-1)
$$

The Nash-equilibrium is stable only if $m<1+\frac{2}{\varepsilon}$. In case of $\varepsilon=0.5$, stability requires that the number of skills and unions are less than five.

For $\sigma>0$ (and $\gamma=1, \phi=0)$, the root $\lambda_{1}=(m-1) \cdot \kappa_{1}$ is given by

$$
\lambda_{1}=-\frac{\left((m-(m-1) \cdot \sigma)^{2} \cdot \frac{\varepsilon}{2-\varepsilon}+\sigma\right)+\sigma \cdot m \cdot(1-\sigma)}{\left((m-(m-1) \cdot \sigma)^{2} \cdot \frac{\varepsilon}{2-\varepsilon}+\sigma\right)+(m-(m-1) \cdot \sigma) \cdot m \cdot(1-\sigma)}
$$

The function is depicted in figure 3 below for $\varepsilon=0.5$ and, respectively, $m=2$ (thick line) and $m=4$ (thin line). The vertical lines depict $\sigma_{\max }=2$ for $m=2$ and $\sigma_{\max }=\frac{4}{3}$ for $m=4$. 


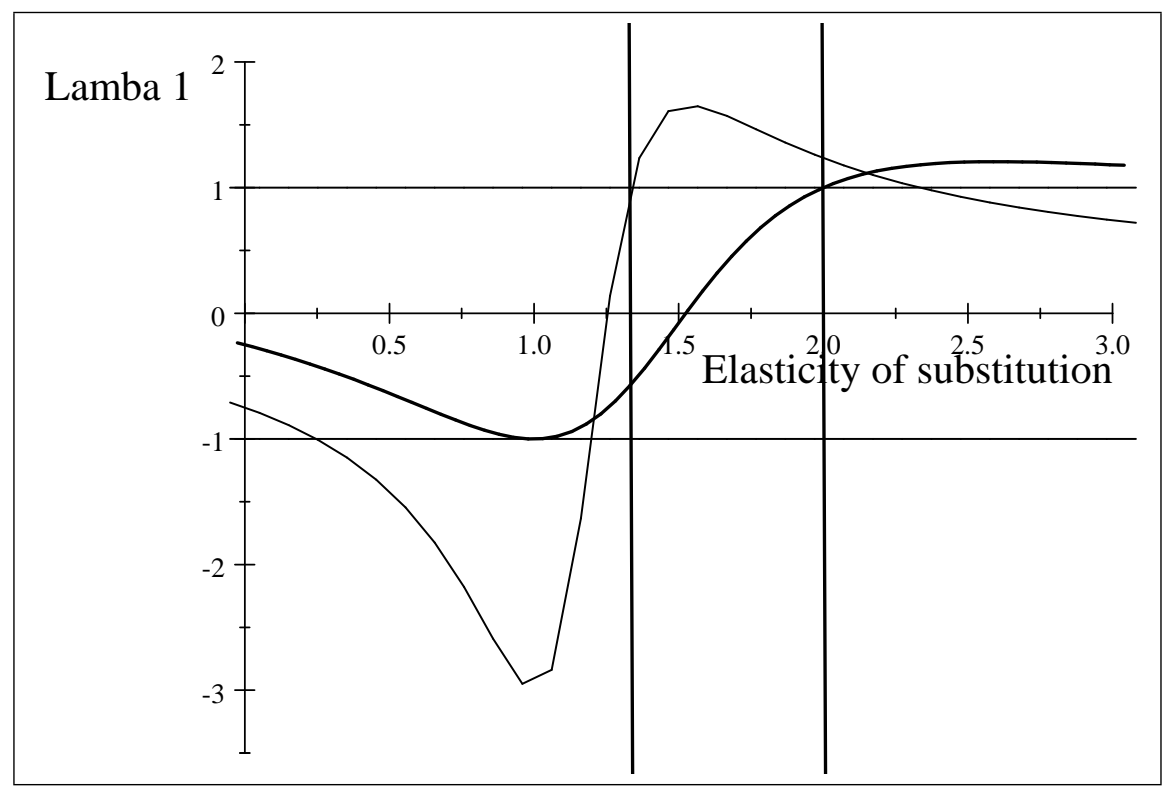

Figure 3: Lambda 1 as a function of the elasticity of substitution. $\mathrm{m}=2$ (thick line), $\mathrm{m}=4$ (thin line).

As illustrated, relaxing the assumption that $\sigma=0$ does not solve the instability problem. On the contrary, the possibility of substitution increases the intrinsic instability of a labor market organized by skills unless $\sigma$ is rather close to $\sigma_{\max }=\left(\frac{m}{m-1}+\phi\right) \cdot \frac{1}{\gamma}$ (the non-negativity condition). The explanation is that intra-skill substitution (competition) makes it even more advantageous to react on other unions' wage increases by lowering its own wage demands.

\subsubsection{Inter-firm competition}

The second term of the largest root of the transition matrix

$$
\lambda_{2}=\kappa_{2} \cdot(n-1) \cdot m=\frac{\frac{a^{2} \cdot(n-1) \cdot m}{n \cdot m \cdot(1-\gamma \cdot \sigma+\phi) \cdot(1-\sigma) \cdot d}}{(m-1)+\frac{(a+d) \cdot a}{m \cdot(1-\gamma \cdot \sigma+\phi) \cdot(1-\sigma) \cdot d}}
$$

is always positive.

In the simple case of $\sigma=0, \gamma=1, \phi=0$ and, consequently, $a=m$, 
$d=1, \lambda_{2}$ and $\lambda=\lambda_{1}+\lambda 2$ reduce to

$$
\begin{aligned}
\lambda_{2} & =\frac{m \cdot(n-1)}{2 \cdot n} \\
\lambda & =-\frac{m-1}{2}+\frac{m \cdot(n-1)}{2 \cdot n}=\frac{n-m}{2 \cdot n} \\
\lambda & >-1 \text { if } m>3 \cdot n
\end{aligned}
$$

Under these simplifying assumptions, a labor market organized in local skill-based unions, $L U$, is unstable only in the highly implausible case that number of skills is larger than three times the number of competing firms.

However in general, inter-firm competition is not sufficient to make a labor market organized by skill stable. Figure 4 below depicts $\lambda_{1}$ (thin dashed line), $\lambda_{2}$ (thin solid line) and $\lambda=\lambda_{1}+\lambda_{2}$ (thick solid line) for $m=4, n=10$, $\varepsilon=0.5, \sigma=0.5, \gamma=1$. The vertical line indicates the maximum value of $\sigma$ consistent with a positive solution.

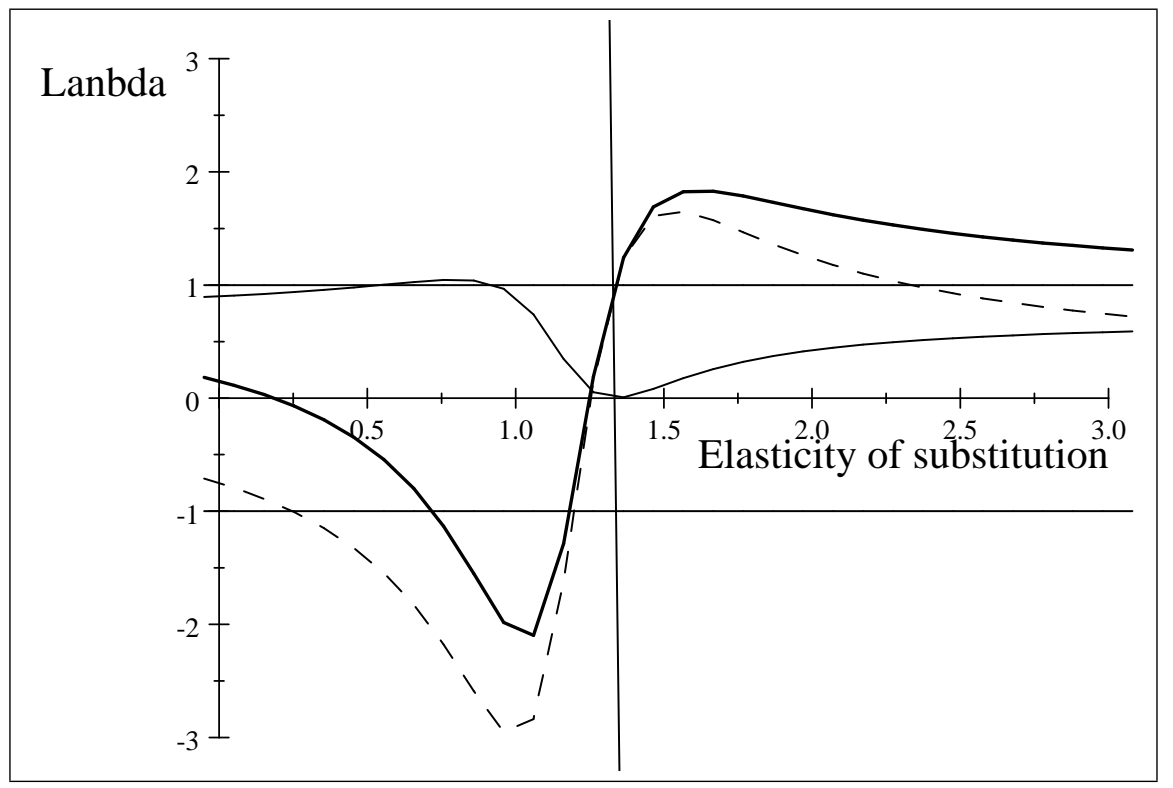

Figure 4: Lambda as a function of the elasticity of substitution (thick solid). Lambda 1 (thin solid), lambda 2 (thin dash).

As illustrated, inter-firm competition $(n>1)$ still leaves a significant range around $\sigma=1$, in which the labor market is unstable. To avoid falling in this 'trap' the unions need to cooperate. 


\subsection{Optimum organization: A cartel of cooperating in- dependent skill-specific unions}

Cooperation is required to reach the optimum wage level and to avoid actions that might destabilize the labor market. However, cooperation is not unproblematic. Forming a cartel that deprives the individual unions of their decision-making power is incentive incompatible ${ }^{14}$.

To see the problem consider the case of the merger of two (formerly) independent unions of unequal size. The governing body is assumed to be democratically elected among selfish members of the two groups and to make decisions according to the one-person-one-vote rule. In this case the decisions of the cartel will reflect only the interests of the larger group. There is no 'median voter' to ensure that a democratic process approaches some reasonable compromise. Thus, if union 1 is the larger one, then the objective function of the cartel, $V_{c}$, effectively reduces to $V_{1}$. On the other hand, the smaller group has the advantage of being small: The cost to the employer of bowing to their demand is smaller and, consequently, the employer is likely to be more inclined to do so (Hersoug 1983). One may argue that these problems can be solved by giving each group the right to veto mutual decisions. However, the right to veto is not credible. After having given up their independent organization, the members of the minor union cannot be confident that the governing body of the joint union will, in fact, comply with such rules after the merger has been effected. With no such guarantee, a joint union is a viable model of union cooperation only if the members of the merging unions have identical skills and interests (and, consequently, it does not matter who makes the decisions $)^{15}$.

Incentive compatibility requires that the individual unions are deprived of incentives to cheat and that the cooperation is organized in a way that allows the cooperating unions to maintain their independent organization and,

\footnotetext{
${ }^{14}$ Holden and Raaum (1991) are pessimistic as to the possibility to reach a cooperatetive solution. They argue that there is a need to coordinate wage moderation but that a binding agreement is difficult to enforce because of lack of credible threats. Joint negotiations aren't possible either because of opposing views on important issues. Hersoug (1983) note that side payments are not easy to imagine and suggests that the unions agree on a proportional reduction relative to the Nash-equilibrium wage rates.

${ }^{15}$ Jun (1989) argues that workers form a joint union when the size or productivity are similar. However, he does not consider the fact that the two groups may not remain of exactly the same size in the future. What is meant by similar productivity is unclear unless the two skills are perfect substitutes.
} 
thereby, the option of withdrawing from the cooperation if the outcome of the joint decisions is less satisfactory than the best alternative non-cooperative outcome. This will be the case if the cooperation is based on the following simple and easily controllable principles:

(1) The competence to negotiate the wage rates for all skills is transferred to the joint body.

(2) In case the unions cannot agree, any wage offer is subject to the general clause that it is not binding until all wage rates have been settled.

\section{Conclusion}

In most countries labor is organized in cooperating skill-specific unions rather than in industrial cartels or totally independent skill-specific unions. Within an extremely simple of a small open economy facing imperfect competition we show that this way of organizing labor can be explained as the outcome of rational (optimizing) behavior on the part of the unions.

Organizing labor in local industrial cartels (regardless of skill) or a single economy-wide cartel results in a real wage level that is inappropriately low both from the point of view of labor and the society as a whole unless labor has close to monopoly power in the wage setting process.

Organizing labor in local or economy-wide skill-specific unions may result in a wage level that is too high. In addition, a labor market organized in non-cooperating unions is likely to be unstable.

This dilemma calls for a compromise: A cartel of cooperating, independent skill-specific unions that enforce agreed demarcations. Cooperation is needed to curb the negative externalities of too high wage rates set by unions that are too strong. Independence (some degree of uncoordinated negotiations between the employers and unions, each of which has the power to inflict considerable loss by calling a strike) is required to produce the necessary pressure on the employers to raise the wage level to the optimum level. And demarcations are required to stabilize the labor marked.

The degree and the form of the cooperation depend inter alia on the bargaining power of the employer, the number of skills and competing firms and the rigidity with which the unions enforce lines of demarcations. 


\section{References}

Andersen, Torben M. and Risager, Ole (1990): Wage formation in Denmark. In L. Calmfors (ed.): Wage Formation in the Nordic Countries. Oxford University Press. 137-81.

Binmore, K., Rubinstein, A and Wolinsky A (1986).: The Nash bargaining solution in economic modelling. Rand Journal of Economics, 17(2), 176-188.

Calmfors, L. and Drifill, J. (1998): Bargaining structure, corporativism and macroeconomic performance. Economic Policy 6, 12-61.

Dowrich, Steve (1989): Union-oligopoly bargaining. The Economic Journal 99, 1123-42.

De Fraja, Giovanni (1993): Staggered vs. synchronised wage setting in oligopoly. European Economic Review 37, 1507-22.

Gylfason, Thorvaldur and Lindbeck Assar (1984): Union rivalry and wages: An oligopolistic approach. Economica 51, 129-39.

Hersoug, T. (1983): The importance of being unimportant - or trade unions strategic positions. Memorandum no. 1. University of Oslo.

Hoel, Michael (1991): Union wage policy: The importance of labor mobility and the degree of centralization. Economica 51, 139-53.

Holden, Steinar and Raaum, Oddbjørn (1991): Wage moderation and union structure. Oxford Economic Papers 43, 409-23.

Horn, Henrik and Wolinsky, Asher (1988): Worker substitutability and patterns of unionisation. The Economic Journal 98, 484-97.

Jun, Byoung Heon (1989): Non-cooperative bargaining and union formation. Review of Economic Studies 56, 59-75.

Machin, Stephen, Mark Steward and Jan van Reenen,(1993): The economic effects of multiple unionism: Evidence from the 1984 Workshop Industrial Relation Survey. The Scandinavian Journal of Economics 95 (3), 279-296

Moene, Karl O. (1988): Unions' threats and wage determination. The Economic Journal 98, 471-83.

Moene, K.O., Wallerstein, N. and Hoel, M. (1993): Bargaining structure and economic performance. In Flanagan, Moene and Wallerstein: Trade union behaviour, pay-bargaining, and economic performance. FIEF Studies in Labour Markets and Economic Policy. Oxford University Press. Clarendon Press. 
Naylor, Robin A. (1995): On the Economic effects of Multiple Unionism. The Scandinavian Journal of Economics 97 (1), 161-167

Oswald, Andrew J. (1979): Wage determination in an economic with many unions. Oxford Economic Papers 31, 183-85.

Pemberton, James (1988): A 'managerial' model of the trade union. The Economic Journal 98 (September 1988), 755-771.

Risager Ole (1993): Labour substitution in Denmark. Oxford Bulletin of Economics and Statistics 55(1), 123-33.

Scheuer, Steen (1992): Denmark: Return to Decentralization. In Ferner A. and Hyman, R. (eds.), Industrial relations in the new Europe. Basil Blackwell

Scheuer, Steen (1998): Denmark, A less regulated model. In Ferner A. and Hyman, R. (eds.), Changing Industrial Relations in Europe. Basil Blackwell 